\title{
The scope of costs in alcohol studies: Cost-of-illness studies differ from economic evaluations
}

Paul F van Gils ${ }^{*+1}$, Heleen H Hamberg-van Reenen+2, Matthijs van den Berg+2, Luqman Tariq ${ }^{+1}$ and G Ardine de Witt1,3

\begin{abstract}
Background: Alcohol abuse results in problems on various levels in society. In terms of health, alcohol abuse is not only an important risk factor for chronic disease, but it is also related to injuries. Social harms which can be related to drinking include interpersonal problems, work problems, violent and other crimes. The scope of societal costs related to alcohol abuse in principle should be the same for both economic evaluations and cost-of-illness studies. In general, economic evaluations report a small part of all societal costs. To determine the cost- effectiveness of an intervention it is necessary that all costs and benefits are included. The purpose of this study is to describe and quantify the difference in societal costs incorporated in economic evaluations and cost-of-illness studies on alcohol abuse.
\end{abstract}

Method: To investigate the economic costs attributable to alcohol in cost-of-illness studies we used the results of a recent systematic review (June 2009). We performed a PubMed search to identify economic evaluations on alcohol interventions. Only economic evaluations in which two or more interventions were compared from a societal perspective were included. The proportion of health care costs and the proportion of societal costs were estimated in both type of studies.

Results: The proportion of healthcare costs in cost-of-illness studies was $17 \%$ and the proportion of societal costs $83 \%$. In economic evaluations, the proportion of healthcare costs was $57 \%$, and the proportion of societal costs was $43 \%$.

Conclusions: The costs included in economic evaluations performed from a societal perspective do not correspond with those included in cost-of-illness studies. Economic evaluations on alcohol abuse underreport true societal cost of alcohol abuse. When considering implementation of alcohol abuse interventions, policy makers should take into account that economic evaluations from the societal perspective might underestimate the total effects and costs of interventions.

\section{Introduction}

Alcohol abuse results in problems on various levels in society. In terms of health, alcohol abuse is not only an important risk factor for chronic disease, but it is also related to unintentional and intentional injuries [1-3]. On the social level the WHO Expert Committee on Problems Related to Alcohol Consumption reported that social harms which can be related to drinking include interpersonal problems, work problems, violent and other crimes [2].

\footnotetext{
* Correspondence: paul.van.gils@rivm.nl

1 National Institute for Public Health and the Environment, Centre for Prevention and Health Services Research, Bilthoven, The Netherlands + Contributed equally

Full list of author information is available at the end of the article
}

From the economic point of view, the estimated tangible costs of alcohol in the European Union were $€ 125$ billion in 2003, including $€ 59$ billion worth of lost productivity through absenteeism, unemployment and lost working years due to premature death [4]. Another study reported that the weighted average costs in four high-income countries (France, USA, Scotland and Canada) were $1.4 \%$ of the gross domestic product [3].

To reduce the negative effect of alcohol abuse it is necessary for countries to develop an alcohol policy and implement prevention programs. An alcohol policy can be defined as a set of measures in a jurisdiction or society aimed at minimizing the health and social problems from alcohol consumption [2]. The alcohol abuse prevention 
programs as developed, focus on one of more of the strategies of the WHO: reducing the availability of alcohol, alcohol prices and taxes, restricting the sale of alcohol, restrictions on alcohol marketing, drink-driving countermeasures, education and persuasion $[2,5]$.

Before an intervention may be implemented, a firm evidence base for its effectiveness is needed. The effects of an intervention should be both statistically significant and clinically relevant.

In light of increasing health care costs and limited resources, interventions aimed at reducing alcohol abuse should not only be effective, but efficient or cost-effective too. Nowadays, policy makers require information about the effectiveness of an intervention in relation to its costs. The perspective of an economic evaluation of an alcohol abuse intervention should be taken into account in the decision making process. If a study is performed from a health care perspective only costs are included which are related to health care use. A study performed from a social perspective includes both healthcare costs and all relevant societal costs. In the case of an alcohol abuse intervention performed from the societal perspective, costs due to productivity losses, crime and law enforcement costs also have to be included, in addition to health care costs. Taking into account the public interest, it is important for a policy maker that all costs related to excessive alcohol use are included in an economic evaluation. In other words: to be able to make a clear decision whether getting good value for the money when introducing a preventive intervention, a policymaker needs economic evaluations that include all related societal costs.

Cost-of illness studies which are performed according to the international guidelines of the WHO report all type of healthcare cost and societal costs comprehensively [6]. From economic evaluations from the societal perspective, it is not known whether all types of societal costs are taken into account. To determine the cost- effectiveness of an intervention it is necessary that all costs and benefits are included. The purpose of this study is to describe the cost components and to quantify the difference in societal costs incorporated in economic evaluations and cost-of-illness studies on alcohol abuse. For the comparison of costs incorporated in economic evaluations and in cost-of-illness studies, we do not focus on marginal cost differences between interventions, but rather concentrate on included pre-intervention costs in economic evaluations only.

\section{Method}

A recently published review summarizes the costs attributable to alcohol abuse as involved in cost-of illness studies [3]. One of the purposes of that review was to analyze the full societal effect of alcohol, since cost-of-illness studies are not restricted to health but usually include criminal outcomes and other social detriments. We selected four of the 29 identified cost-of-illness studies. Those studies were methodologically most comparable i.e. those estimating the gross costs and using the same discount rate. Those were studies of high income countries (France, US, Scotland and Canada). We calculated the per-study (unweighted) average proportion of health care costs and societal costs of those four cost-of-illness studies [3]. The types of costs involved in those studies are: total healthcare costs, prevention and research costs, public order and safety costs, criminal damage costs, drink-driving costs, work-related costs, the loss of revenues from compulsory taxes, property damage and premature mortality in the non working population. For the per-study average proportion of healthcare costs, we counted total health care costs and prevention and research costs. To have an estimate of the total societal costs, we counted all other type of costs.

To identify economic evaluations on alcohol interventions, we performed a PubMed search. The search contained the terms: alcohol abuse, alcohol misuse, economic evaluation, cost-effectiveness, cost-utility, life year gained, QALY, prevention, preventive intervention and societal perspective. We searched for economic evaluations that were reported between 2000 and 2009 in English. We only included full economic evaluations performed from the societal perspective in which two or more interventions on alcohol abuse were compared with each other or with usual care [7]. Of the included studies the per-study (unweighted) average proportion of healthcare cost and societal costs at baseline were calculated for the intervention groups. The proportion of the health care costs and the proportion of the societal costs were compared in both cost-of-illness studies and economic evaluations.

To be able to compare the outcomes of cost-of-illness studies and economic evaluations with different base years and different currency units, all local currencies were first transferred to the euro currency values of that time, following the advice of the Organization for Economic Co-operation and Development, and then recalculated to 2008 , the year that was chosen as base year for the current study $[8,9]$.

\section{Results}

\section{Cost-of-illness studies}

Table 1 shows the results of the cost-of-illness studies. Differences in types of societal costs that were included in the four investigated cost-of-illness studies were observed. All studies included public order and safety costs and work-related (productivity) costs, and all but one study did include drink-driving costs $[10,12]$. Productivity costs were estimated using the 'human capital' 
Table 1: The costs as reported in four included cost-of-illness studies (recalculated into million 2008€) and the proportion Health Care costs and Societal costs (\%)

\begin{tabular}{|c|c|c|c|c|c|c|c|c|c|c|c|c|}
\hline Study & $\begin{array}{l}\text { Healthcare } \\
\text { costs }\end{array}$ & $\begin{array}{l}\text { Prevention } \\
\text { and } \\
\text { research } \\
\text { costs }\end{array}$ & $\begin{array}{l}\text { Total } \\
\text { Health Care } \\
\text { costs }\end{array}$ & $\begin{array}{c}\text { Proportion } \\
\text { Health care } \\
\text { costs (\%) }\end{array}$ & $\begin{array}{c}\text { Public } \\
\text { order and } \\
\text { safety costs }\end{array}$ & $\begin{array}{c}\text { Criminal } \\
\text { damage } \\
\text { costs }\end{array}$ & $\begin{array}{l}\text { Drink-driving } \\
\text { costs }\end{array}$ & $\begin{array}{l}\text { Work-related } \\
\text { costs }\end{array}$ & $\begin{array}{l}\text { Cost of the } \\
\text { losses in } \\
\text { compulsory } \\
\text { taxes }\end{array}$ & $\begin{array}{c}\text { Total } \\
\text { Societal } \\
\text { costs }\end{array}$ & $\begin{array}{l}\text { Proportion } \\
\text { societal } \\
\text { costs }\end{array}$ & $\begin{array}{l}\text { Total } \\
\text { costs }\end{array}$ \\
\hline $\begin{array}{l}\text { Fenoglio } \\
\text { (France) }\end{array}$ & 3,500 & 698 & 4,198 & 19 & 70 & & 4,393 & 10,936 & 2,333 & 17,732 & 81 & 21,930 \\
\hline $\begin{array}{l}\text { Harwood } \\
\text { (USA) }\end{array}$ & 28,074 & 1,860 & 29,934 & 15 & 779 & 8,966 & 17,948 & 141,497 & & 164,811 & 85 & 198,345 \\
\hline $\begin{array}{l}\text { Varney } \\
\text { (Scotland) }\end{array}$ & 155 & 3 & 158 & 9 & 142 & 442 & & 1025 & & 1,608 & 91 & 1,766 \\
\hline $\begin{array}{c}\text { Rehm } \\
\text { (Canada) }\end{array}$ & 2,678 & 110 & 2,788 & 24 & 2,488 & 127 & 613 & 5,772 & & 9,001 & 76 & 11,789 \\
\hline
\end{tabular}


Table 2: The types of baseline costs as reported in five economic evaluations (2008€) and the proportion Health Care costs and Societal costs (\%)

\begin{tabular}{|c|c|c|c|c|c|c|c|c|c|c|c|c|c|}
\hline Study & & $\begin{array}{l}\text { Healthcare } \\
\text { costs }\end{array}$ & $\begin{array}{l}\text { Prevention } \\
\text { and research } \\
\text { costs }\end{array}$ & $\begin{array}{c}\text { Total } \\
\text { Heath } \\
\text { Care costs }\end{array}$ & $\begin{array}{c}\text { Proportion } \\
\text { Health Care } \\
\text { costs (\%) }\end{array}$ & $\begin{array}{c}\text { Public } \\
\text { order and } \\
\text { safety costs }\end{array}$ & $\begin{array}{c}\text { Criminal } \\
\text { damage } \\
\text { costs }\end{array}$ & $\begin{array}{l}\text { Drink- } \\
\text { driving } \\
\text { costs }\end{array}$ & $\begin{array}{l}\text { Work- } \\
\text { related } \\
\text { costs }\end{array}$ & $\begin{array}{l}\text { Cost of the } \\
\text { losses in } \\
\text { compulsory } \\
\text { taxes }\end{array}$ & $\begin{array}{c}\text { Total } \\
\text { societal } \\
\text { cost }\end{array}$ & $\begin{array}{l}\text { Proportion } \\
\text { Societal } \\
\text { costs (\%) }\end{array}$ & $\begin{array}{l}\text { Total } \\
\text { costs }\end{array}$ \\
\hline Barrett & & 4,523 & & 4,523 & 53 & 3,146 & 665 & & 153 & & 3,964 & 47 & 8,487 \\
\hline \multirow[t]{2}{*}{ Parrott ${ }^{1}$} & Intervention 1 & 1,087 & 74 & 1,161 & 35 & 69 & 2,099 & & & & 2,168 & 65 & 3,329 \\
\hline & Intervention 2 & 2,367 & 627 & 2,994 & 60 & 274 & 1,759 & & & & 2,033 & 40 & 5,027 \\
\hline Rychlik & & 1,666 & 10 & 1,676 & 77 & & & & 488 & & 488 & 23 & 2,164 \\
\hline Solberg & & 2,418 & & 2,418 & 33 & 5,007 & & & & & 5,007 & 67 & 7,425 \\
\hline \multirow[t]{2}{*}{ UKATT ${ }^{1}$} & Intervention 1 & 2,678 & & 2,678 & 74 & 83 & 856 & & & & 939 & 26 & 3,617 \\
\hline & Intervention 2 & 2,991 & & 2,991 & 70 & 144 & 1130 & & & & 1,274 & 30 & 4,265 \\
\hline
\end{tabular}


approach. Other societal types of costs were only reported in one cost-of-illness study [13].

Averaged over all the cost-of-illness studies, the proportion of the healthcare costs was $17 \%$ of the total cost due to alcohol abuse. The societal costs attributed to $83 \%$ of the total alcohol abuse costs.

\section{Economic evaluations}

Our literature search on economic evaluations of preventive interventions directed at alcohol abuse conducted in July 2009, identified 116 potentially relevant studies. After having read the abstracts, we selected 34 articles to read in full, of those we included 5 studies because these studies satisfied our inclusion criterion $[14,18]$. Reasons for excluding 29 studies were that those were not performed from a societal perspective or were not full economic evaluations. One of included studies was a modeling study [17], the other four were original research. Two of the studies used the QALY as an outcome measure $[17,18]$, while the other studies presented the outcome in surrogate endpoints: reduction in alcohol consumption $[14,15]$ or number of successfully treated persons [16].

Table 2 shows the types of costs involved in the economic evaluations and the absolute cost figures. Healthcare costs were reported in all included economic evaluations, and prevention and research costs were included in four of five economic evaluations [14,17]. Focusing on societal costs, there were large differences in types of costs that were included. Four studies included public order and safety costs $[14,15,17,18]$, and two studies included work related costs, using the 'human capitol' approach. There were no studies that included drinkdriving costs and costs of losses in compulsory taxes. We only report the cost components and the absolute costs before the start of an intervention and do not pay attention to incremental or marginal costs.

Averaged over all economic evaluations the proportion of the healthcare costs at baseline was $57 \%$ of the total cost, and of the societal costs amounted for $43 \%$.

\section{Discussion}

Our study shows that the scope of societal costs included in five economic evaluations with a societal perspective was smaller than the scope of societal costs as incorporated in four cost-of-illness studies. We found only 5 fulleconomic evaluation studies on preventive interventions of alcohol abuse. None of the economic evaluations included all types of societal costs that were represented in the cost-of-illness studies. This means that, although it is claimed that the societal perspective is taken, the societal costs as reported in economic evaluations are incomplete in general. In relation to alcohol abuse it is remarkable that none of the studies included drink-driv- ing costs. Only two studies included work-related costs due to productivity losses. These results corresponds with the findings of Barbosa et al. that a societal perspective has never been taken into full account in economic evaluations [19]. The four cost-of-illness studies used to identify the healthcare and societal costs of alcohol abuse present those costs clearly in general. The only exception is that Fenoglio et al. did not include criminal damage [13].

Averaged over all economic evaluations, the proportion of healthcare costs (57\%) and societal cost (43\%) does not correspond with the proportion as reported in cost-of-illness studies (17\% and $83 \%$, respectively). So, the incremental cost-effectiveness ratios (ICER) that are reported in economic evaluations might be underestimations of the true societal costs and effects of preventive interventions directed at alcohol abuse.

It is known that economic evaluations of alcohol abuse interventions performed from a healthcare perspective underestimate true costs, because only healthcare costs are involved in this kind of studies. It will be useful to policy makers if studies make clear how a life-style intervention directed towards alcohol abuse affects both the health care costs and the societal costs [20]. Studies that claim to be done from a societal perspective show an underestimation too. The real part of societal costs will be much higher than presented in those economic evaluations.

Comparing productivity costs between studies is hampered by the existence of two 'schools' that address the issue of valuation of productivity losses in an entirely different manner. Advocates of the friction cost approach come-up with relatively modest estimates of productivity losses, whereas those using the human capital approach may easily reach estimates that are ten to hundred times higher than those generated by frictionists. There is no easy solution to this problem, and both approaches may hold best arguments, depending on the local circumstances of the analysis. In the meantime, absolute clarity about methodology used to derive productivity costs estimates is indispensable.

Two studies presented the QALY as an outcome. In studies done from a healthcare perspective the QALY as an outcome measure is almost standard practice. Although economic evaluations presenting the QALY as outcome measure are more or less comparable with each other, the way the QALY is measured in a public-health intervention performed from a societal perspective is debatable. The questionnaires to estimate the QALY are directed on health status, while in a societal perspective also other benefits besides healthcare, like social welfare, should be involved; these are not included in those questionnaires [21]. In general, it will be useful to think about the method used to make an economic evaluation of pub- 
lic health programs. Recent literature gives arguments to change from the cost effectiveness/cost-utility analyses to cost-benefit analyses (CBA). CBA does assess how social welfare is affected by an intervention, by identifying and measuring all costs and benefits. All gains, also health gains, are expressed in monetary terms [22]. Clearly this would represent a more holistic approach to evaluation of different alcohol policy measures. However, for obvious reasons, $\mathrm{CBA}$ is rare in all economic evaluations, not only for those of public health programmes.

Some limitations of this study have to be taken into account. We calculated per-study averaged total healthcare costs and societal costs, but it is quite difficult to compare costs as reported in different economic evaluations. This was due to differences in study design, outcome measures, discount rates, et cetera. For example, three studies used 'preventing the decrease of drinking' and 'abstinence' as a surrogate outcome measure. Another limitation is that the cost-of-illness studies showed also differences in the types of costs involved in the studies. That means that a full comparison of the studies is not really possible, although these studies are more complete than the economic evaluations. Furthermore, in the original studies, it is not always clear which costs are placed under the types of costs. It will be possible that 'property damage' costs for instance are placed under the topic 'criminal damage'.

\section{Conclusion}

The costs included in economic evaluations on alcohol abuse interventions performed from a societal perspective do not correspond with those included in cost-of-illness studies on alcohol abuse. It is obvious that alcohol abuse not only affects health care costs, but has also a big influence on societal costs. Productivity losses account for the largest proportion of the total costs. Therefore, it is important that all economic evaluations report productivity costs in the same way, to ensure comparability among studies.

Policy makers need to have data based on real life, i.e. all societal costs (next to all health care costs) should be included in economic evaluations from the societal perspective. It can be concluded from the results of this study, that this is not the case in most economic evaluations. In considering whether good value for the money is achieved when introducing a preventive intervention, policy makers should take into account that the result from an economic evolution from the societal perspective might be an underestimation of the true costs and effects of the intervention.

\section{Competing interests}

The authors declare that they have no competing interests.

\section{Authors' contributions}

PFVG and MVDB developed the method of the study. All the authors helped to draft the manuscript, read and approved the final manuscript.

\section{Author Details}

${ }^{1}$ National Institute for Public Health and the Environment, Centre for Prevention and Health Services Research, Bilthoven, The Netherlands, ${ }^{2}$ National Institute for Public Health and the Environment, Centre for Public Health Forecasting, Bilthoven, The Netherlands and ${ }^{3}$ Julius Centre for Health Sciences and Primary Care, University Medical Centre Utrecht, The Netherlands

Received: 8 March 2010 Accepted: 6 July 2010

Published: 6 July 2010

References

1. Room R, Babor T, Rehm J: Alcohol and public health. Lancet 2005, 365:519-530.

2. WHO Expert Committee on Problems Related to Alcohol Consumption. Second report. World Health Organ Tech Rep Ser 2007:1-53. 55-57, back cover

3. Rehm J, Mathers C, Popova S, Thavorncharoensap M, Teerawattananon Y, Patra J: Global burden of disease and injury and economic cost attributable to alcohol use and alcohol-use disorders. Lancet 2009, 373:2223-2233.

4. Anderson P, Baumberg B: Alcohol in Europe. London: Institute of Alcohol Studies; 2006

5. WHO: Strategies to reduce the harmful use of alcohol. Secretariat 61st World Health Assembly 2008

6. Single E, Collins D, Easton B, Harwood H, Lapsley H, Kopp P, Wilson E: International guidelines for estimating the costs of substance abuse (second edition). Geneva: World Health Organization; 2003.

7. Drummond MF, Sculpher MJ, Torrance GW, Stoddart GL: Methods for economic evaluation of health care programmes. Third edition. Oxford: Oxford University Press; 2005.

8. Purchasing Power Parities (PPPs) for OECD Countries since 1980 [http:/ /stats.oecd.org/Index.aspx?datasetcode=SNA TABLE4]

9. Consumentenprijsindices (CPI) alle huishoudens, $2000=100$ http: $/ /$ statline.cbs.nl/StatWeb/publication/ $? \mathrm{VW}=\mathrm{T} \& \mathrm{DM}=\mathrm{SLNL} \& \mathrm{PA}=71311 \mathrm{ned} \& \mathrm{D} 1=0-1,4-$ 5\&D2=0\&D3=a\&HD=080514-1109\&HDR=T\&STB=G2]

10. Varney SJ, Guest JF: The annual societal cost of alcohol misuse in Scotland. Pharmacoeconomics 2002, 20:891-907.

11. Harwood H: Updating Estimates of the Economic Costs of Alcohol Abuse in the United States: Estimates, Update Methods, and Data. Report prepared by The Lewin Group for the National Institute on Alcohol Abuse and Alcoholism, 2000. Based on estimates, analyses, and data reported in Harwood, H.; Fountain, D.; and Livermore, G. The Economic Costs of Alcohol and Drug Abuse in the United States 1992. Report prepared for the National Institute on Drug Abuse and the National Institute on Alcohol Abuse and Alcoholism. National Institutes of Health, Department of Health and Human Services. NIH Publication No. 98-4327. Rockville, MD: National Institutes of Health; 2000.

12. Rehm J, Gnam W, Popova S, Baliunas D, Brochu S, Fischer B, Patra J, Sarnocinska-Hart A, Taylor B: The costs of alcohol, illegal drugs, and tobacco in Canada, 2002. J Stud Alcohol Drugs 2007, 68:886-895.

13. Fenoglio P, Parel V, Kopp P: The social cost of alcohol, tobacco and illicit drugs in France, 1997. Eur Addict Res 2003, 9:18-28.

14. Barrett B, Byford S, Crawford MJ, Patton R, Drummond C, Henry JA, Touquet R: Cost-effectiveness of screening and referral to an alcohol health worker in alcohol misusing patients attending an accident and emergency department: a decision-making approach. Drug Alcohol Depend 2006, 81:47-54.

15. Parrott S, Godfrey C, Heather N, Clark J, Ryan T: Cost and outcome analysis of two alcohol detoxification services. Alcohol Alcohol 2006 41:84-91.

16. Rychlik R, Siedentop H, Pfeil T, Daniel D: Cost-effectiveness of adjuvant treatment with acamprosate in maintaining abstinence in alcohol dependent patients. Eur Addict Res 2003, 9:59-64.

17. Solberg LI, Maciosek MV, Edwards NM: Primary care intervention to reduce alcohol misuse ranking its health impact and cost effectiveness. Am J Prev Med 2008, 34:143-152. 
18. UKATT: Cost effectiveness of treatment for alcohol problems: findings of the randomised UK alcohol treatment trial (UKATT). Bmj 2005, 331:544.

19. Barbosa C, Godfrey C, Parrott S: Methodological assessment of economic evaluations of alcohol treatment: what is missing? Alcohol Alcohol 2009, 45:53-63.

20. Jonsson B: Ten arguments for a societal perspective in the economic evaluation of medical innovations. Eur J Health Econ 2009, 10:357-359.

21. Weatherly H, Drummond M, Claxton K, Cookson R, Ferguson B, Godfrey C, Rice N, Sculpher M, Sowden A: Methods for assessing the costeffectiveness of public health interventions: Key challenges and recommendations. Health Policy 2009, 93:85-92.

22. Cohen DR, Patel N: The Potential to Forgo Social Welfare Gains through Overrelianceon Cost Effectiveness/Cost Utility Analyses in the Evidence Base for Public Health. J Environ Public Health 2009, 2009:107927.

doi: $10.1186 / 1478-7547-8-15$

Cite this article as: van Gils et al. The scope of costs in alcohol studies: Costof-illness studies differ from economic evaluations Cost Effectiveness and Resource Allocation 2010, 8:15

Submit your next manuscript to BioMed Central and take full advantage of:

- Convenient online submission

- Thorough peer review

- No space constraints or color figure charges

- Immediate publication on acceptance

- Inclusion in PubMed, CAS, Scopus and Google Scholar

- Research which is freely available for redistribution 